\title{
1,3-Propanediol production in a two-step process fermentation from renewable feedstock
}

\author{
Filipa Soares Mendes • Maria González-Pajuelo • \\ Hélène Cordier • Jean M. François • Isabel Vasconcelos
}

\begin{abstract}
In this work, the production of 1,3-propanediol from glucose and molasses was studied in a two-step process using two recombinant microorganisms. The first step of the process is the conversion of glucose or other sugar into glycerol by the metabolic engineered Saccharomyces cerevisiae strain HC42 adapted to high $\left(>200 \mathrm{~g} \mathrm{l}^{-1}\right)$ glucose concentrations. The second step, carried out in the same bioreactor, was performed by the engineered strain Clostridium acetobutylicum DG1 (pSPD5) that converts glycerol to 1,3-
\end{abstract}

F. S. Mendes $(\bowtie) \cdot M$. González-Pajuelo $\cdot$ I. Vasconcelos $\mathrm{CBQF} /$ Centro de Biotecnologia e Química Fina,

Escola Superior de Biotecnologia,

Universidade Católica Portuguesa,

Rua Dr. António Bernardino de Almeida,

4200-072 Porto, Portugal

e-mail: fsmendes@mail.esb.ucp.pt

H. Cordier · J. M. François

INSA, UPS, INP, Université de Toulouse,

135 Avenue de Rangueil,

31077 Toulouse, France

J. M. François

INRA, UMR792 Ingénierie des Systèmes

Biologiques et des Procédés,

31077 Toulouse, France

J. M. François

CNRS, UMR5504,

31400 Toulouse, France

Present Address:

M. González-Pajuelo

Ablynx SA,

Rua Campo Alegre,

4150-180 Porto, Portugal propanediol. This two-step strategy led to a flexible process, resulting in a 1,3-propanediol production and yield that depended on the initial sugar concentration. Below $56.2 \mathrm{~g} \mathrm{l}^{-1}$ of sugar concentration, cultivation on molasses or glucose showed no significant differences. However, at higher molasses concentrations, glycerol initially produced by yeast could not be totally converted into 1,3-propanediol by $C$. acetobutylicum and a lower 1,3-propanediol overall yield was observed. In our hand, the best results were obtained with an initial glucose concentration of $103 \mathrm{~g} \mathrm{l}^{-1}$, leading to a final 1,3-propanediol concentration of $25.5 \mathrm{~g} \mathrm{l}^{-1}$, a productivity of $0.16 \mathrm{~g} \mathrm{l}^{-1} \mathrm{~h}^{-1}$ and 1,3-propanediol yields of $0.56 \mathrm{~g} \mathrm{~g}^{-1}$ glycerol and $0.24 \mathrm{~g} \mathrm{~g}^{-1}$ sugar, which is the highest value reported for a two-step process. For an initial sugar concentration (from molasses) of $56.2 \mathrm{~g} \mathrm{l}^{-1}, 27.4 \mathrm{~g} \mathrm{l}^{-1}$ of glycerol were produced, leading to $14.6 \mathrm{~g} \mathrm{l}^{-1}$ of 1.3-propanediol and similar values of productivity, $0.15 \mathrm{~g} \mathrm{l}^{-1} \mathrm{~h}^{-1}$, and overall yield, $0.26 \mathrm{~g} \mathrm{~g}^{-1}$ sugar.

Keywords Molasses · Glycerol · 1,3-Propanediol · Two-step fermentation - Saccharomyces cerevisiae . Clostridium acetobutylicum

\section{Introduction}

The nowadays crisis of crude oil market and its correlative environmental problems toughens industrial biotechnology as an alternative to the chemical industries for production of petroleum-based chemicals. The state-of-the-art of white biotechnology offers the possibility of using renewable feedstocks for the production of synthons like 1,3-propanediol (1,3-PD). Due to its simple chemical structure, it can be used in a wide range of applications. One of the most relevant is the production of polyesters, namely polytrimethylene terephthalate (Biebl et al. 1999; González-Pajuelo et al. 2006; 
Rao et al. 2008), but it can also be used in food, cosmetics, medicines (one of its derivatives can be used to reduce rejection of transplanted organs (Németh and Sevella 2008)). Traditional production of 1,3-PD is based on chemical synthesis from petroleum derivatives compounds, which requires expensive production processes and yields toxic intermediates, like acrolein. In contrast, 1,3-PD can be produced by fermentation of relatively low-cost renewable carbon sources, and this process, though maybe more expensive than the chemical process, provides radical solutions to environmental pollution and petroleum depletion. The microbiologically produced $1,3-\mathrm{PD}$ has properties superior to chemically synthesized 1,3-PD, such as a lower amount of impurities (Kurian 2005). In addition, the polyesters based on the biological 1,3-PD are fully biodegradable.

One of the big challenges of the white biotechnology is to find cheap processes and renewable resources to reduce the overall cost of final products, turning them highly competitive to chemical-based products. A natural pathway for the production of 1,3-PD is from glycerol which takes place in a few bacteria species (e.g., Clostridium butyricum, Clostridium pasteurianum, Citrobacter freundii, Klebsiella pneumoniae, Lactobacillus brevis, Lactobacillus buchneri, Bacillus welchii, and Enterobacter agglomerans) (Barbirato et al. 1995; Biebl et al. 1992, 1999; Boenigk et al. 1993; Dabrock et al. 1992; Daniel et al. 1995; Forsberg 1987; Homann et al. 1990; Schutz and Radler 1984). With the expansion of biofuel production, glycerol, which represents a secondary product, may become an abundant and cheap source for the biological production of 1,3-PD. Papanikolaou et al. (2000) showed that equivalent growth characteristics were obtained for batch cultures of C. butyricum F2b on pure or raw glycerol, from the biodiesel production process. A 1,3-PD yield of around $0.55 \mathrm{~g} \mathrm{~g}^{-1}$ of glycerol was observed for batch and chemostat cultures on raw glycerol; $48 \mathrm{~g}^{-1}$ of 1,3-PD were produced from $90 \mathrm{~g} \mathrm{l}^{-1}$ of raw glycerol, at a dilution rate of $0.02 \mathrm{~h}^{-1}$, and a volumetric productivity of $5.5 \mathrm{~g} \mathrm{l}^{-1} \mathrm{~h}^{-1}$ was obtained for a dilution rate of $0.21 \mathrm{~h}^{-1}$. In order to reach simultaneously high volumetric productivity and product concentration, a two-stage continuous fermentation may be used, where the first reactor operates with a high dilution rate to achieve a high productivity and a low dilution rate is applied to the second reactor to increase product concentration. This strategy led to a 1,3-PD production of 41-46 $\mathrm{g}^{-1}$ by $C$. butyricum $\mathrm{F} 2 \mathrm{~b}$, growing on raw glycerol, with an overall volumetric productivity of $3.4 \mathrm{~g} \mathrm{l}^{-1} \mathrm{~h}^{-1}$ as the highest value (Papanikolaou et al. 2000, 2008). González-Pajuelo et al. (2004) showed that C. butyricum VPI 3266 presented the same tolerance to raw and to commercial glycerol, when both had a similar grade (above $87 \% \mathrm{w} / \mathrm{v}$ ); however, a $39 \%$ increase of growth inhibition was observed in the presence of
$100 \mathrm{~g} \mathrm{l}^{-1}$ of $65 \%(w / v)$ grade raw glycerol. C. acetobutylicum DG1 (pSPD5), an engineered strain able to produce 1,3-PD from glycerol, also exhibited similar fermentation patterns on commercial $(87 \% \mathrm{w} / \mathrm{v})$ and raw $(65 \% \mathrm{w} / \mathrm{v})$ glycerol (González-Pajuelo et al. 2005). Hirschmann et al. (2005) reported a final 1,3-PD concentration of $87 \mathrm{~g} \mathrm{l}^{-1}$ and a productivity of $2.2 \mathrm{~g} \mathrm{l}^{-1} \mathrm{~h}^{-1}$ in fed-batch cultures of a wild-type Clostridium strain IK124 on treated raw glycerol. Economic production of 1,3-PD from raw glycerol may be possible with optimized operating conditions and novel technological strategies, but the main unknown cost factor is the strongly fluctuating glycerol market (Willke and Vorlop 2008). Thus, facing the instability of the glycerol and petroleum market, the evaluation of alternative cheap sources for the biological production of 1,3-PD should be considered.

Sugars are a desirable renewable carbon source, but no natural microorganism has been found that can directly convert sugars to 1,3-PD. Different approaches have been suggested as possible solutions to this issue. The first approach is to engineer the pathway for the conversion of sugars to 1,3-PD in a single organism (Biebl et al. 1999; Cameron et al. 1998). However, this strategy is not satisfactory since the production of 1,3-PD by metabolic engineered S. cerevisiae or $K$. pneumoniae was only 0.4 or 1.2 and $0.58 \mathrm{~g} \mathrm{l}^{-1}$, respectively (Ma et al. 2009; Rao et al. 2008; Zheng et al. 2008). Dupont and Genencor developed a glucose-based process using a recombinant Escherichia coli carrying the genes for the production of glycerol from $S$. cerevisiae and the genes for the production of 1,3-PD from $K$. pneumoniae. 1,3-PD was produced with a titter of $135 \mathrm{~g} \mathrm{l}^{-1}$ (Nakamura and Whited 2003); however, this process is dependent on the addition of vitamin B12 inflating the cost of the production process. Other strategy is to use one microorganism to convert sugars to glycerol and another to convert glycerol to 1,3-PD. This can be achieved through a one-step process using mixed cultures, but microbial repression of 1,3-propanediol production by glucose appears not to be favorable and the use of genetically modified microorganisms to suppress the repression of 1,3-PD formation is needed (Biebl et al. 1999; Cameron et al. 1998). A two-step process strategy represents a third approach that has been already tried either by a recombinant $E$. coli or by a yeast strain to produce glycerol in the first step and $K$. pneumoniae to convert glycerol into 1,3-PD in the second step (Cheng et al. 2006; Hartlep et al. 2002). However, the 1,3-PD yield reached was not high (0.41-0.53 $\mathrm{g} \mathrm{g}^{-1}$ of glycerol) and according to Hartlep et al. (2002), the overall 1,3-PD yield from glucose in the two-step process was $0.17 \mathrm{~g} \mathrm{~g}^{-1}$. In addition, $K$. pneumoniae is known as a facultative pathogen which limits its application in industry. 
In this work, we have considered a two-step process from glucose or sugar molasses using a yeast strain engineered for maximal glycerol yield, followed by the production of 1,3-propanediol using an engineered $C$. acetobutylicum strain. The process should be flexible and able to operate either on glycerol or on sugar feedstocks according to the market situation.

\section{Materials and methods}

Yeast and bacterial strains

To produce glycerol from glucose in the first step, the metabolically engineered $S$. cerevisiae strain $\mathrm{HC} 42$, described by Cordier et al. (2007), was used. In this strain, originated from the wild-type auxotrophic strain of the diploid CEN.PK2 family (van Dijken et al. 2000), the gene GPD1, encoding a $\mathrm{NAD}^{+}$-dependent glycerol 3-phosphate dehydrogenase, was overexpressed, as well as $A L D 3$, encoding a cytosolic $\mathrm{NAD}^{+}$-dependent aldehyde dehydrogenase; to increase the availability of NADH, TPII, encoding a triose phosphate isomerase was deleted; this genetic intervention was used to flow half of the glucose into the glycerol pathway; also, to increase the NADH available for glycerol production, $A D H 1$, that encodes the major $\mathrm{NAD}^{+}$dependent alcohol dehydrogenase, was deleted. Two other yeast strains, FH100 and FH200, resulting from the adaptation of HC42 to high glucose concentrations, were also used. The adaptation to high glucose concentrations was obtained by streaking the HC42 strain on yeast Malt (YM) broth (from Difco) supplemented with agar and different glucose concentrations $\left(50,100\right.$, and $\left.200 \mathrm{~g} \mathrm{l}^{-1}\right)$ and incubating for several days until appearance of isolated colonies. The colonies were randomly selected and then streaked again on plates with the same medium; this procedure was repeated several times. The adapted strain was able to grow in liquid medium with high glucose concentrations (100 and $200 \mathrm{~g} \mathrm{l}^{-1}$ ).

In the second step of the process, the production of 1,3-PD from glycerol was carried out by the engineered strain $C$. acetobutylicum DG1 (pSPD5) described by González-Pajuelo et al. (2005). This strain was obtained by introducing the pSPD5 plamid (Raynaud et al. 2003), carrying the 1,3propanediol operon genes from C. butyricum, in the mutant strain $C$. acetobutylicum DG1. The strain DG1, originated from the wild-type strain C. acetobutylicum ATCC 824, is unable to produce solvents and sporulate. As a result, $C$. acetobutylicum DG1 (pSPD5) can grow on glycerol as the sole carbon source, and the major product of this fermentation is 1,3-PD.

These organisms were stored in $20 \%(v / v)$ glycerol at $-80^{\circ} \mathrm{C}$ and used to inoculate pre-cultures for experiments.
Fermentation conditions

\section{S. cerevisiae fermentation}

The inocula were prepared in a 1-1 Erlen flask containing 0.51 of synthetic defined medium (SD) prepared as follows (1 1 of medium): yeast nitrogen base without amino acids and ammonium sulphate (YNB, Difco, Detroit, USA), $1.7 \mathrm{~g}$; $\left(\mathrm{NH}_{4}\right)_{2} \mathrm{SO}_{4}, 5 \mathrm{~g}$; L-arginine, $0.02 \mathrm{~g}$; threonine, $0.05 \mathrm{~g}$, L-tryptophan, $0.04 \mathrm{~g}$; L-isoleucine, $0.06 \mathrm{~g}$; lysine, $0.04 \mathrm{~g}$; methionine, $0.01 \mathrm{~g}$; phenylalanine, $0.06 \mathrm{~g}$; tyrosine, $0.05 \mathrm{~g}$, adenine, $0.01 \mathrm{~g}$; histidine, $0.01 \mathrm{~g}$, uracil, $0.01 \mathrm{~g} ; 2 \%$, $10 \%$, or $20 \%$ of glucose or sugar cane molasses were added to SD medium as carbon source. Molasses were obtained from a sugar company (Refinarias de Açúcar Reunidas, S.A.) in Porto, Portugal. The medium was inoculated at $8 \%(v / v)$, and after $24 \mathrm{~h}$ incubation in a rotary shaker, at $30^{\circ} \mathrm{C}$ and $150 \mathrm{rpm}$, yeast cells were harvested by centrifugation, resuspended in SD medium, and reinoculated into a 2-1 bioreactor (Biostat MD, Braun, Melsungen, Germany), containing 1.51 of SD medium, at an initial $0 \mathrm{D}_{600}$ of $0.05-0.1 \mathrm{U}$. Silicon antifoaming agent (Merck) was used when needed at a concentration of $0.1 \mathrm{ml} \mathrm{l}^{-1}$ of culture. SD medium was completed with glucose (20 to $200 \mathrm{~g} \mathrm{l}^{-1}$ ) or with sugar cane molasses. Molasses contained around $50 \%(w / v)$ of total sugars (TS) (sucrose $82.7 \%$, glucose $7.7 \%$, fructose $5.9 \%$, and raffinose $3.7 \%$ ). Cultures were carried out at $30^{\circ} \mathrm{C}$, at different $\mathrm{pH}$ values $(4,5.0$, and 6.5$)$, aeration rates $(0.5,1.0$, and $1.5 \mathrm{vvm})$, and agitation speed (150 and $300 \mathrm{rpm})$. The $\mathrm{pH}$ was controlled by automatic addition of $\mathrm{NaOH} 1 \mathrm{M}$.

\section{C. acetobutylicum fermentation}

The second step of the process was carried out by $C$. acetobutylicum in the same bioreactor. Inocula of $C$. acetobutylicum ( $10 \% v / v$ inoculation with a stock culture) were grown in the synthetic liquid medium described by González-Pajuelo et al. (2005) with $4 \mathrm{~g} \mathrm{l}^{-1}$ yeast extract. The inoculation of the bioreactor was carried out at $10 \%$ $(v / v)$ with a growing culture at the early exponential growth phase. To assure the anaerobic environment needed for bacterium growth, yeast broth was degassed by sparging sterile $\mathrm{O}_{2}$-free nitrogen for $8-10 \mathrm{~h}(1.5$ vvm). Yeast cells were not removed from the culture broth. The gas outlet of the bioreactor was connected with a pyrogallol arrangement (Vasconcelos et al. 1994), which trapped any oxygen entry. The initial culture $\mathrm{pH}$ was set at 6.5 by $\mathrm{NH}_{4} \mathrm{OH} 6 \mathrm{~N}$ addition. To reduce culture lag phase, no $\mathrm{pH}$ regulation and agitation were turned on until the culture reached the exponential growth phase. Only then, $\mathrm{pH}$ was maintained at 6.5 by automatic addition of $\mathrm{NH}_{4} \mathrm{OH} 6 \mathrm{~N}$ and stirred at $100 \mathrm{rpm}$. The temperature was set at $35^{\circ} \mathrm{C}$, and the culture was continuously flushed with 
sterile $\mathrm{O}_{2}$-free nitrogen $(0.1 \mathrm{vvm})$, to maintain anaerobiosis during the fermentation process. No additional supplements were added to the yeast broth resulting from the first step of the process.

\section{Analytical procedures}

Yeast cell concentration was measured by optical density at $600 \mathrm{~nm}\left(\mathrm{OD}_{600}\right)$ and cell dry weight measurements. A correlation was established between both methods. For cultivations in molasses, the number of yeast cells, expressed as colony-forming units per milliliter, was determined using the plate count method, after incubation of the plates at $30^{\circ} \mathrm{C}$ for $48 \mathrm{~h}$ on rich medium containing $1 \%(w / v)$ yeast extract, $2 \%(w / v)$ peptone, $2 \%(w / v)$ glucose, and $2 \%(w / v)$ agar.

Substrates and fermentation end-product concentrations were determined by high performance liquid chromatography (HPLC), which included glucose, fructose, sucrose, raffinose, glycerol, succinate, acetate, acetoin, acetaldehyde, ethanol, glycerol, 1,3-PD, and butyrate. To this end, a sample of the fermentation broth was centrifuged, and the supernatant was filtered through $0.22 \mu \mathrm{m}$ pore size nylon filters prior to perform the separation on a Bio-Rad Aminex column HPX-87H $(300 \times 7.8 \mathrm{~mm}$; Richmond, California, USA). Operating conditions were as follows: mobile phase, $1 \mathrm{mM}$ sulphuric acid; flow rate, $0.5 \mathrm{ml} \mathrm{min}{ }^{-1}$; temperature, $30^{\circ} \mathrm{C}$; and the detection was achieved by refractive index. Glycerol concentration was also determined by an enzymatic analysis. The BoehringerMannheim enzymatic kit for glycerol analysis (Cat. No. 148 270) was used to confirm results from HPLC analysis and for lower concentrations, under the HPLC detection limit.

\section{Results}

S. cerevisiae $\mathrm{HC} 42$ adaptation to high glucose concentrations

In order to produce glycerol from high sugar concentrations by the genetically modified yeast strain $\mathrm{HC} 42$, cultivation on $100 \mathrm{~g} \mathrm{l}^{-1}$ of glucose was performed. However, the strain was not able to grow on a media with such a high glucose concentration. Therefore, we searched for individual clones from this engineered strain able to grow in the presence of high glucose concentrations. The strategy was quite simple since we firstly streaked $\mathrm{HC} 42$ onto $\mathrm{YM}$ agar plates containing $50 \mathrm{~g} \mathrm{l}^{-1}$ of glucose. After 1 week, individual clones were transferred to plates with the same medium. Seven days later, the $50 \mathrm{~g} \mathrm{l}^{-1}$ glucose adapted clone was streaked onto YM agar plates containing $100 \mathrm{~g} \mathrm{l}^{-1}$ of glucose. After two further transfers onto the same agar plates, several individual clones were picked and cultivated in liquid media in the presence of $100 \mathrm{~g} \mathrm{l}^{-1}$ of glucose. One of them, showing the fastest growth in these conditions, and termed FH100, was streaked onto an YM agar plate containing $200 \mathrm{~g} \mathrm{l}^{-1}$ of glucose and incubated for a week. After two more transfers into the same medium ( 7 days of incubation before transfer), individual clones were cultivated in liquid medium with $200 \mathrm{~g} \mathrm{l}^{-1}$ of glucose. The strain obtained was called FH200. At higher glucose concentration, the selected FH200 clone could weakly grow on agar plates containing $400 \mathrm{~g} \mathrm{l}^{-1}$ glucose, but not on liquid media with the same glucose concentration.

Glycerol production by non-adapted and adapted $S$. cerevisiae to high glucose concentration

As a first step in setting up the fermentation condition for glycerol production, we evaluated the effects of agitation rate (150 and $300 \mathrm{rpm})$, aeration flow $(0.5,0.1$, and 1.5 $\mathrm{vvm})$, and $\mathrm{pH}(4.0,5.0$, and 6.5$)$ on various macrokinetic parameters including rate and yield of glycerol production, using the metabolically engineered strain $\mathrm{HC} 42$ cultivated in SD medium with $20 \mathrm{~g} \mathrm{l}^{-1}$ of glucose at $30^{\circ} \mathrm{C}$. As indicated in Table 1, at an agitation rate of $150 \mathrm{rpm}$, none of these culture conditions affected the final glycerol yield, and only slight effects of $\mathrm{pH}$ and aeration rate were noticed on ethanol and acetate yields. However, increasing the agitation rate to $300 \mathrm{rpm}$ resulted in a dramatic reduction of the glucose consumption rate, and hence increased by 3.5 fold, the cultivation time for complete sugar fermentation, although final yield of glycerol was not impaired.

Similar results were obtained with the adapted strain FH100, yielding after $40 \mathrm{~h}$ of cultivation $0.48 \mathrm{~g}$ glycerol produced per gram glucose (data not shown).

Based on the results attained with the strain $\mathrm{HC} 42$ at low glucose concentrations, an aeration rate of $0.5 \mathrm{vvm}$, an agitation rate of $150 \mathrm{rpm}$, and a $\mathrm{pH}$ of 6.5 were chosen to test for glycerol production by FH100 and FH200 at high glucose concentrations (Figs. 1 and 2). As expected, glycerol was the major fermentation end-product, as it was for strain $\mathrm{HC} 42$, yielding $0.47 \mathrm{~g} \mathrm{~g}^{-1}$ of glucose for FH100 and $0.40 \mathrm{~g} \mathrm{~g}^{-1}$ of glucose for FH200, likely because this strain was unable to consume all the glucose in the medium. Ethanol, acetate, succinate, acetoin, and acetaldehyde were also found among cultivation end-products. The biomass produced by the strain FH100 $\left(1.1 \mathrm{~g} \mathrm{l}^{-1}\right)$ was almost the same as the value reached by the strain FH200 $\left(1.3 \mathrm{~g} \mathrm{l}^{-1}\right)$. The growth rate was higher for strain FH100 than for FH200, reaching 0.11 and $0.08 \mathrm{~h}^{-1}$, respectively. A fed-batch culture of FH100 did not result in an improved glycerol production (data not shown). To conclude, S. cerevisiae FH100 and FH200 could be cultivated on 100 and $200 \mathrm{~g} \mathrm{l}^{-1}$ glucose leading to a fivefold increase of final glycerol concentration. 
Table 1 Effect of $\mathrm{pH}$, aeration flow, and agitation rate on S. cerevisiae HC42 batch cultivation (SD medium with $20 \mathrm{~g} 1^{-1}$ of glucose, temperature of $30^{\circ} \mathrm{C}$ )

\begin{tabular}{|c|c|c|c|c|c|c|}
\hline \multirow{3}{*}{$\begin{array}{l}\text { Agitation (rpm) } \\
\text { Aeration (vvm) } \\
\text { pH }\end{array}$} & \multicolumn{5}{|l|}{150} & \multirow{3}{*}{$\begin{array}{l}300 \\
0.5 \\
5.0\end{array}$} \\
\hline & \multicolumn{3}{|l|}{0.5} & \multirow{2}{*}{$\begin{array}{l}1.0 \\
5.0\end{array}$} & \multirow{2}{*}{$\begin{array}{l}1.5 \\
5.0\end{array}$} & \\
\hline & 4.0 & 5.0 & 6.5 & & & \\
\hline Residual glucose $\left(\mathrm{g}^{-1}\right)$ & $0.23 \pm 0.08$ & $0.02 \pm 0.0$ & $0.02 \pm 0.01$ & $0.02 \pm 0.01$ & $0.04 \pm 0.02$ & $0.02 \pm 0.00$ \\
\hline Glycerol concentration $\left(\mathrm{g} \mathrm{l}^{-1}\right)$ & $9.6 \pm 0.2$ & $9.4 \pm 0.4$ & $9.5 \pm 0.2$ & $9.4 \pm 0.2$ & $9.7 \pm 0.1$ & $9.3 \pm 0.1$ \\
\hline Biomass concentration $\left(\mathrm{g} \mathrm{l}^{-1}\right)$ & $1.23 \pm 0.11$ & $1.31 \pm 0.30$ & $0.96 \pm 0.10$ & $1.63 \pm 0.34$ & $2.14 \pm 0.15$ & $1.42 \pm 0.41$ \\
\hline \multicolumn{7}{|l|}{ Products yield ( $\mathrm{g} \mathrm{g}^{-1}$ glucose) } \\
\hline Glycerol & $0.47 \pm 0.01$ & $0.46 \pm 0.02$ & $0.47 \pm 0.00$ & $0.47 \pm 0.02$ & $0.47 \pm 0.02$ & $0.45 \pm 0.03$ \\
\hline Ethanol & $0.05 \pm 0.03$ & $0.06 \pm 0.00$ & $0.04 \pm 0.01$ & $0.02 \pm 0.00$ & $0.02 \pm 0.01$ & nd \\
\hline Acetate & $0.01 \pm 0.00$ & $0.01 \pm 0.00$ & $0.03 \pm 0.00$ & $0.02 \pm 0.00$ & nd & $0.01 \pm 0.00$ \\
\hline$\mu_{\max }\left(\mathrm{h}^{-1}\right)$ & $0.19 \pm 0.02$ & $0.18 \pm 0.03$ & $0.12 \pm 0.02$ & $0.18 \pm 0.01$ & $0.18 \pm 0.03$ & $0.21 \pm 0.02$ \\
\hline$r_{\text {glucose }}\left(\mathrm{g} \mathrm{l}^{-1} \mathrm{~h}^{-1}\right)$ & $0.48 \pm 0.04$ & $0.53 \pm 0.04$ & $0.48 \pm 0.05$ & $0.37 \pm 0.03$ & $0.42 \pm 0.05$ & $0.13 \pm 0.02$ \\
\hline Cultivation time (h) & $42.0 \pm 5.7$ & $38.0 \pm 3.5$ & $43.5 \pm 4.4$ & $50.0 \pm 4.7$ & $44.0 \pm 5.1$ & $157.0 \pm 8.6$ \\
\hline
\end{tabular}

Results are the mean values \pm standard deviation from at least four determinations

$\mu_{\max }$ maximum specific growth rate $\left(\mathrm{h}^{-1}\right.$; slope of the least squares regression line of the natural logarithm of optical density vs. time data during the exponential growth phase), $r_{\text {glucose }}$ maximum volumetric glucose uptake rate $\left(\mathrm{g} \mathrm{l}^{-1} \mathrm{~h}^{-1}\right), n d$ not detected

Cultivation of S. cerevisiae strains HC42 and FH100 on molasses media

Strains HC42 and FH100 were also cultivated on sugar cane molasses media, using the same aeration flow, agitation rate, and $\mathrm{pH}$ conditions than cultures on $\mathrm{SD}$ media. As for cultivation on SD medium, glycerol was the major fermentation end-product (Table 2). The strain $S$. cerevisiae FH100 seemed to grow better on $10 \%$ molasses (56.2 $\left.\mathrm{g} \mathrm{l}^{-1} \mathrm{TS}\right)$. The growth rate $\left(0.13 \mathrm{~h}^{-1}\right)$ and the biomass concentration $\left(2.2 \mathrm{~g} \mathrm{l}^{-1}\right)$ were higher at this molasses concentration and decreased when higher sugar concentrations were used (growth rate $0.10 \mathrm{~h}^{-1}$ and biomass concentration of $1.3 \mathrm{~g} \mathrm{l}^{-1}$ ). The strain HC42 grew slightly better on molasses medium than in SD medium, with a biomass production of $2.48 \mathrm{~g} \mathrm{l}^{-1}$. The production of glycerol increased with the initial total sugars (TS) concentration, from $12.7 \mathrm{~g} \mathrm{l}^{-1}$, when the strain HC42 was cultivated on $5 \%$ molasses $\left(27.6 \mathrm{~g}^{-1} \mathrm{TS}\right)$, to $47.1 \mathrm{~g} \mathrm{l}^{-1}$, when strain FH100 was grown on an initial molasses concentration of $20 \%$ (101.3 $\left.\mathrm{g} \mathrm{l}^{-1} \mathrm{TS}\right)$. However, glycerol yield was the same for all fermentations, $0.47-0.48 \mathrm{~g} \mathrm{~g}^{-1}$ of sugar. Other fermentation end-products were acetate and ethanol; succinate, acetoin $\left(0.02 \mathrm{~g} \mathrm{~g}^{-1} \mathrm{TS}\right)$, and acetaldehyde $\left(0.01 \mathrm{~g} \mathrm{~g}^{-1} \mathrm{TS}\right)$ were also detected in the final broth (data not shown).

\section{1,3-Propanediol production on yeast broths}

Production of 1,3-propanediol was assayed by inoculating C. acetobutylicum DG1 (pSPD5) in yeast fermentation broth that contained glycerol obtained from glucose or sugar cane molasses conversion. Various initial concentrations of carbon sources, originating broths with different glycerol concentrations, were tested. C. acetobutylicum was able to grow on the cultures broths from glucose or from sugar cane molasses without any prior medium treatment, except for degassing with sterile $\mathrm{O}_{2}$-free nitrogen. For low initial sugar concentrations, $22 \mathrm{~g}^{-1}$ of glucose and $27.6 \mathrm{~g} \mathrm{l}^{-1}$ of molasses TS, i.e., 13.4 and $14 \mathrm{~g} \mathrm{l}^{-1}$ of glycerol, respectively, results were similar (Table 3). 1,3-PD yield was $0.57 \mathrm{~g} \mathrm{~g}^{-1}$ of glycerol, and $0.25-0.26 \mathrm{~g} \mathrm{~g}^{-1}$ of sugar, and around $95 \%$ of the initial glycerol was consumed. In glucose broth, it was possible to cultivate C. acetobutylicum on $103 \mathrm{~g} \mathrm{l}^{-1}$ of initial glucose concentration, reaching $25.5 \mathrm{~g} \mathrm{l}^{-1}$ of 1,3-PD, with $88 \%$ of glycerol consumption and yields of $0.56 \mathrm{~g} \mathrm{~g}^{-1}$ glycerol and $0.24 \mathrm{~g} \mathrm{~g}^{-1}$ glucose; the 1,3-PD productivity obtained was $0.16 \mathrm{~g} \mathrm{l}^{-1} \mathrm{~h}^{-1}$. For an initial concentration of TS of $56.2 \mathrm{~g} \mathrm{l}^{-1}$ in molasses broth, $14.6 \mathrm{~g} \mathrm{l}^{-1}$ of 1,3-PD were obtained, with a productivity of $0.15 \mathrm{~g} \mathrm{l}^{-1} \mathrm{~h}^{-1}$ and yield values of $0.58 \mathrm{~g} \mathrm{~g}^{-1}$ glycerol and $0.26 \mathrm{~g} \mathrm{~g}^{-1}$ sugar. When higher sugar concentrations (77.8 and $101.3 \mathrm{~g} \mathrm{l}^{-1}$ ) were used in the first step, an inhibitory effect on bacteria's growth was found for molasses broth, and a considerable residual glycerol concentration was observed in the medium.

\section{Discussion}

In order to implement a two-step process for 1,3-propanediol production from glucose using at the first step, a metabolic 

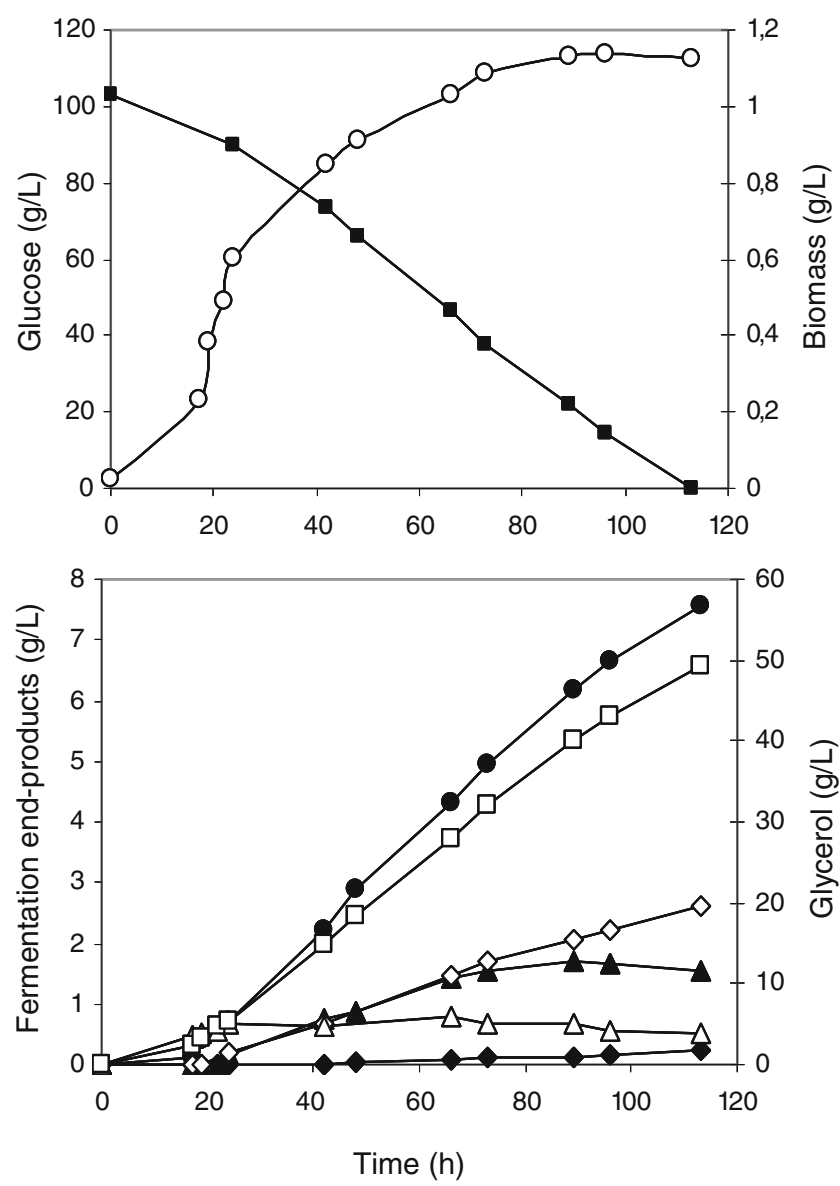

Fig. 1 S. cerevisiae FH100 batch cultivation in SD medium with $100 \mathrm{~g} \mathrm{l}^{-1}$ glucose, at $\mathrm{pH} 6.5,30^{\circ} \mathrm{C}, 150 \mathrm{rpm}$ and $0.5 \mathrm{vvm}$. Glucose (filled square), ethanol (filled circle), acetate (filled triangle), succinate (filled diamond), biomass (empty circle), glycerol (empty square), acetoin (empty diamond), acetaldehyde (empty triangle)

engineered yeast for glycerol production followed by an engineered Clostridium strain to convert it to 1,3-PD, we had to solve two major issues. A first one was to optimize the conditions for maximal glycerol production from high sugar concentration and the second one was to verify whether conversion of glycerol to 1,3-PD was possible by direct inoculation of the bacterial strain in the fermentation broth. With respect to the first issue, we found that the major parameter that could impair efficient fermentation of glucose into glycerol was the agitation rate. It is known that agitation rate favors oxygen supply to the cells, and in this study, this can be the cause of the low glucose uptake rate and the 3.5fold increase of cultivation time, when the agitation rate was $300 \mathrm{rpm}$. Increasing aeration rate resulted in a slight enhancement of biomass production that was accompanied by a reduction of the glucose uptake rate and of ethanol and acetate yields. This indicates that oxygen was more available to cells to stimulate the aerobic metabolism resulting in higher ATP availability for biomass production. These results are reminiscent to the so-called Pasteur effect (aerobic inhibition of glycolysis) (Lloyd et al. 1983). In S. cerevisiae, the Pasteur effect is especially effective under slow growth condition, as upon nitrogen limitation (Lagunas et al. 1982). Interestingly, this glycerol-engineered S. cerevisiae mutant strain exhibits a growth rate twofold lower than the wild-type and hence its global physiology can be more sensitive to oxygen availability than the isogenic wild type.

The use of high sugar concentrations in the cultivation medium was an obvious choice to enhance the production of glycerol. However, glycerol-engineered S. cerevisiae $\mathrm{HC} 42$ was found unable to grow in the presence of more than $20 \mathrm{~g} \mathrm{l}^{-1}$ of glucose. By selecting spontaneous clones able to grow on 100 and $200 \mathrm{~g} \mathrm{l}^{-1}$ glucose, we isolated adapted strains that were able to grow in sugar medium containing up to $200 \mathrm{~g}^{-1}$ glucose. Yeast strains HC42 and FH100 were able to grow in sugar cane molasses, but only FH100 was able to grow on $20 \%$ molasses $w / v$, which contained up to $100 \mathrm{~g}^{-1}$ TS. This adapted strain showed
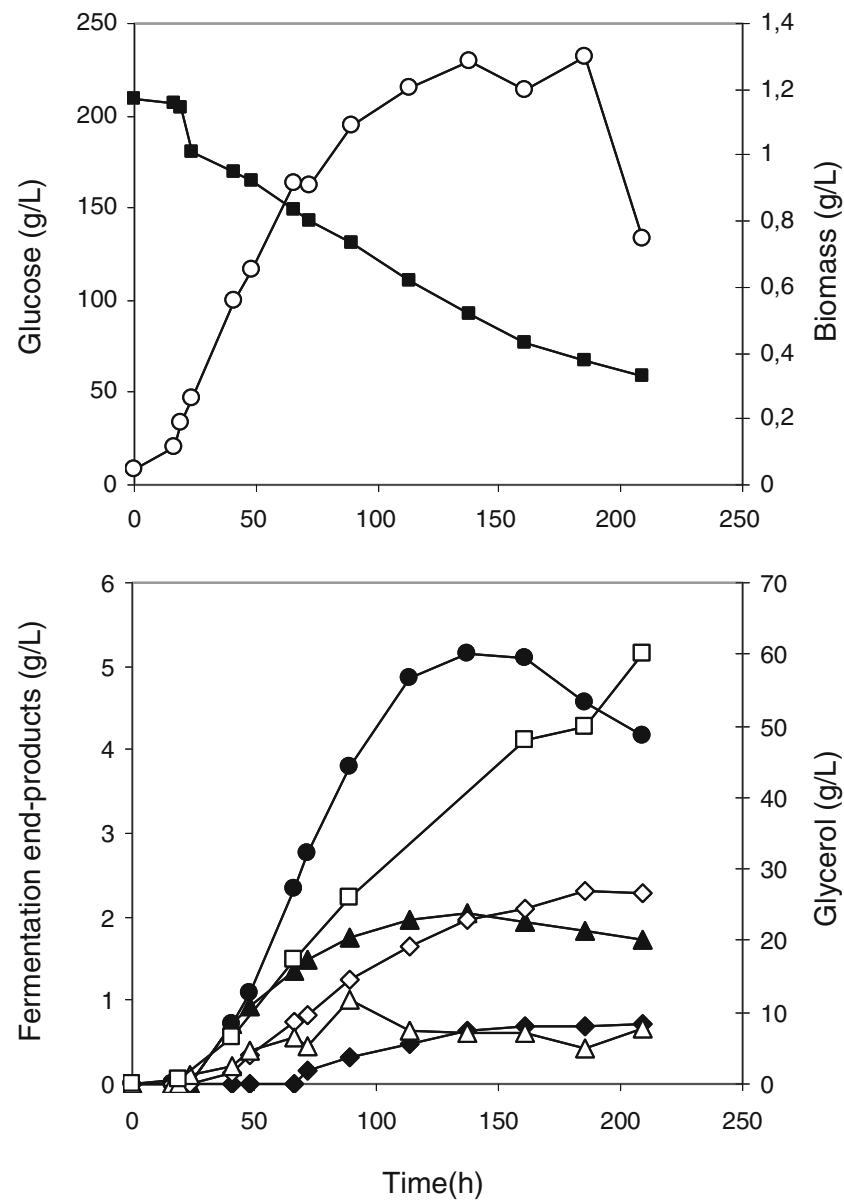

Fig. 2 S. cerevisiae FH200 batch cultivation in SD medium with $200 \mathrm{~g} \mathrm{l}^{-1}$ glucose, at $\mathrm{pH} 6.5,30^{\circ} \mathrm{C}, 150 \mathrm{rpm}$, and $0.5 \mathrm{vvm}$. Glucose (filled square), ethanol (filled circle), acetate (filled triangle), succinate (filled diamond), biomass (empty circle), glycerol (empty square), acetoin (empty diamond), acetaldehyde (empty triangle) 
Table 2 S. cerevisiae HC42 and FH100 batch cultivations in molasses medium with different initial sugar concentrations at $\mathrm{pH} 6.5,30^{\circ} \mathrm{C}$, aeration $0.5 \mathrm{vvm}$, and $150 \mathrm{rpm}$

\begin{tabular}{lcccc}
\hline & HC42 & FH100 & \\
\hline Sugar cane molasses $(w / v)$ & $5 \%$ & $10 \%$ & $15 \%$ & $20 \%$ \\
Initial TS concentration $\left(\mathrm{g} \mathrm{l}^{-1}\right)$ & 27.6 & 56.2 & 77.8 & 101.3 \\
Glycerol concentration $\left(\mathrm{g} \mathrm{l}^{-1}\right)$ & 12.7 & 25.8 & 36.8 & 47.6 \\
Biomass concentration $\left(\mathrm{g} \mathrm{l}^{-1}\right)$ & 2.48 & 2.22 & 1.27 & 1.25 \\
Products yield $\left(\mathrm{g} \mathrm{g}^{-1}\right.$ of sugar) & & & & \\
Glycerol & 0.47 & 0.48 & 0.48 & 0.47 \\
Ethanol & 0.07 & 0.07 & 0.08 & 0.07 \\
Acetate & 0.03 & 0.03 & 0.04 & 0.05 \\
$\mu_{\text {max }}\left(\mathrm{h}^{-1}\right)$ & 0.14 & 0.13 & 0.10 & 0.10 \\
Glycerol productivity $\left(\mathrm{g} \mathrm{l}^{-1} \mathrm{~h}^{-1}\right)$ & 0.24 & 0.34 & 0.25 & 0.30 \\
\hline
\end{tabular}

$T S$ total sugars, $\mu_{\max }$ maximum specific growth rate $\left(\mathrm{h}^{-1}\right.$; slope of the least squares regression line of the natural logarithm of colonyforming units per milliliter vs. time data during the exponential growth phase), $n d$ not detected

reduced growth rate only at high sugar concentration either because of the high osmotic pressure of these media or because of an inhibitory effect due to some by-products, that can be acetaldehyde, since the amount of acetaldehyde in these culture conditions could reach up to $0.6-1.0 \mathrm{~g}^{-1}$. This concentration is within the range showed to exert inhibition (Heux et al. 2006; Remize et al. 1999, 2001). In a previous work with $S$. cerevisiae, the increase in molasses concentration resulted in a significant decrease of growth rate, biomass yield, and ethanol productivity, although with a higher range of concentrations tested (from 96.7 till $323.5 \mathrm{~g}^{-1}$ ) (Atiyeh and Duvnjak 2003).

For the second issue, we found that direct inoculation of an engineered strain of C. acetobutylicum DG1 (pSPD5) into the culture broth successfully converted glycerol previously produced by yeast into 1,3-PD. This required only the degassing of the medium by sparging sterile $\mathrm{O}_{2}$ free nitrogen for several hours to assure the strict anaerobic conditions needed for C. acetobutylicum growth. However, the process only operated efficiently using a synthetic growth medium with 20 or $100 \mathrm{~g}$ glucose per liter, or a molasses medium with up to $56.2 \mathrm{~g} \mathrm{l}^{-1}$ of sugar, but not on medium with higher concentrations of sugar molasses. In this latter situation, the rate of conversion of glycerol into 1,3-PD was strongly inhibited, suggesting the presence of inhibitors of $C$. acetobutylicum fermentation in sugar molasses. This can be due to high levels of salt as it was shown in a previous work using blackstrap molasses for the production of acetone and butanol by $C$. acetobutylicum; the presence of high level of salts in the molasses affected the microorganism's growth and the final product concentration (Fouad et al. 1982). It is also described by Jiang et al. (2009) that molasses contain considerable amounts of metal ions like calcium, zinc, sodium, iron, magnesium, manganese, copper, etc., and also suspended colloids that can cause critical problems during fermentation as they can impair microorganism's growth, influence substrate $\mathrm{pH}$, and are involved in the inactivation of enzymes associated with product biosynthesis. Furthermore, melanoidins and other pigments present in molasses, which are toxic and hardly decomposed compounds (Chandra et al. 2008), may also affect glycerol conversion to 1,3-PD by C. acetobutylicum .

C. butyricum was able to ferment glycerol from different industrial sources with high efficiency; a 1,3-PD yield of $0.49 \mathrm{~g} \mathrm{~g} \mathrm{~g}^{-1}$ was obtained on glycerol coming from concentrated wine stillage and no significant inhibitory effect on cells' growth was noticed; moreover, $63.4 \mathrm{~g} \mathrm{l}^{-1}$ of 1,3-PD were achieved on glycerol issued from industrial ester production (Barbirato et al. 1998).

In the present work, best results were obtained with an initial glucose concentration of $103 \mathrm{~g} \mathrm{l}^{-1}$, leading to a final 1,3-propanediol concentration of $25.5 \mathrm{~g} \mathrm{l}^{-1}$ and yields of $0.56 \mathrm{~g} \mathrm{~g}^{-1}$ of glycerol $\left(0.67 \mathrm{~mol} \mathrm{~mol}^{-1}\right)$ and $0.24 \mathrm{~g} \mathrm{~g}^{-1}$ glucose.

Similar results were reported by González-Pajuelo et al. (2005) with the same strain, in continuous cultures with commercial $(87 \% w / v)$ and raw glycerol $(65 \% w / v)$. The 1,3-PD yield obtained was 0.53 and $0.51 \mathrm{~g} \mathrm{~g}^{-1}$ on

Table 3 Batch cultures of C. acetobutylicum DG1 (pSPD5) on different yeast broths, at $\mathrm{pH} 6.5,35^{\circ} \mathrm{C}$, and $100 \mathrm{rpm}$

\begin{tabular}{|c|c|c|c|c|c|c|}
\hline \multirow[t]{2}{*}{ Yeast strain } & \multicolumn{2}{|c|}{ Yeast broth from SD medium } & \multicolumn{4}{|c|}{ Yeast broth from sugar cane molasses } \\
\hline & $\mathrm{HC} 42$ & FH100 & $\mathrm{HC} 42$ & FH100 & & \\
\hline Sugar concentration $\left(\mathrm{g} \mathrm{l}^{-1}\right)$ & 22.0 & 103.0 & 27.6 & 56.2 & 77.8 & 101.3 \\
\hline Initial glycerol concentration $\left(\mathrm{g}^{-1}\right)$ & 13.4 & 51.8 & 14.0 & 27.4 & 37.8 & 48.1 \\
\hline Residual glycerol $\left(\mathrm{g} \mathrm{l}^{-1}\right)$ & 0.77 & 5.95 & 0.73 & 2.1 & 14.9 & 40.3 \\
\hline 1,3-PD concentration $\left(\mathrm{g}^{-1}\right)$ & 7.16 & 25.5 & 7.63 & 14.6 & 12.7 & 4.3 \\
\hline 1,3-PD yield ( $\mathrm{g} \mathrm{g}^{-1}$ of glycerol) & 0.57 & 0.56 & 0.57 & 0.58 & 0.55 & 0.55 \\
\hline $1,3-\mathrm{PD}$ overall yield ( $\mathrm{g} \mathrm{g}^{-1}$ of sugar) & 0.25 & 0.24 & 0.26 & 0.26 & 0.18 & 0.04 \\
\hline 1,3-PD productivity $\left(\mathrm{g} \mathrm{l}^{-1} \mathrm{~h}^{-1}\right)$ & 0.12 & 0.16 & 0.12 & 0.15 & 0.05 & 0.08 \\
\hline
\end{tabular}


commercial and on raw glycerol, respectively. Papanikolaou et al. (2008) obtained a $47.1 \mathrm{~g} \mathrm{l}^{-1}$ final concentration of 1,3-PD, with a yield of $0.53 \mathrm{~g} \mathrm{~g}^{-1}$, in a batch fermentation of $90 \mathrm{~g}^{-1}$ of raw glycerol by $C$. butyricum F2b. In chemostat cultures, the same strain was able to produce $48 \mathrm{~g} \mathrm{l}^{-1}$ of 1,3-PD from raw glycerol, with similar yield and a volumetric productivity of $0.96 \mathrm{~g} \mathrm{l}^{-1} \mathrm{~h}^{-1}$; 1,3-PD global productivity was improved to $3.4 \mathrm{~g} \mathrm{l}^{-1} \mathrm{~h}^{-1}$ in a two-stage steady-state continuous fermentation of raw glycerol and the 1,3-PD concentration remained at 41-46 g l$~^{-1}$ (Papanikolaou et al. 2000). The two-stage continuous culture strategy was also applied by Boenigk et al. (1993) to the conversion of commercial glycerol to 1,3-PD by $C$. freundii DSM 30040, reaching a final concentration of $41 \mathrm{~g} \mathrm{l}^{-1}$ and a global productivity of $1.38 \mathrm{~g} \mathrm{l}^{-1} \mathrm{~h}^{-1}$. These productivity values are higher than those obtained with the novel two-step process used in this work.

In a previous work, where $K$. pneumoniae was directly inoculated onto yeast broth in batch cultivation, Cheng et al. (2006) reported a 1,3-PD productivity of $0.89 \mathrm{~g} \mathrm{~h}^{-1} \mathrm{l}^{-1}$ and a yield of $0.36 \mathrm{~g} \mathrm{~g}^{-1}$ glycerol which represented a final 1,3-PD concentration of $21.6 \mathrm{~g} \mathrm{l}^{-1}$. In the same work, using a fed-batch process with electrodialytically pre-treated glycerol broth as substrate, $53 \mathrm{~g}^{-1}$ of $1,3-\mathrm{PD}$ were achieved with a yield of $0.41 \mathrm{~g} \mathrm{~g}^{-1}$ glycerol and a productivity of $0.94 \mathrm{~g} \mathrm{l}^{-1} \mathrm{~h}^{-1}$. Hartlep et al. (2002) also described a two-step batch process for 1,3-PD production from glucose. In this case, K. pneumoniae was directly inoculated onto $E$. coli glycerol broth to obtain $14.1 \mathrm{~g}^{-1}$ 1,3-PD with a yield of $0.53 \mathrm{~g} \mathrm{~g}^{-1}$ of glycerol and a productivity of $2.0 \mathrm{~g} \mathrm{l}^{-1} \mathrm{~h}^{-1}$. The overall 1,3-PD yield from glucose in the two-step process was $0.17 \mathrm{~g} \mathrm{~g}^{-1}$. Taken together, the overall yield obtained in our work was higher than those previously published using a twostep process, either on glucose or molasses broth, reaching up to $0.24-0.26 \mathrm{~g} \mathrm{~g}^{-1}$ respectively, but the productivity was lower. The bacterial strain used in this work may be too sensitive to inhibitors present in molasses broth. A treatment like sulphuric acid treatment method should be implemented to remove heavy metals from molasses. Another concern related to molasses use is that molasses and molasses wastewater contain high concentration of organic matters and a large amount of dark pigments such as melanoidins (Chandra et al. 2008; Sirianuntapiboon and Prasertsong 2008). These colored substances are hardly decomposed or decolorized by bio-sludge of both conventional aerobic and anaerobic wastewater treatment systems such as the activated sludge system or anaerobic contact digestion, although some bacterial treatments have been investigated (Chandra et al. 2008; Kumar and Chandra 2006; Sirianuntapiboon and Prasertsong 2008; Tondee and Sirianuntapiboon 2008). This issue must be considered when molasses are used as raw material.
The strategy followed in this work showed the possibility of using renewable feedstocks as carbon sources for the production of 1,3-PD. The fact that two steps were developed, using genetically modified strains of $S$. cerevisiae for the conversion of sugar into glycerol and of $C$. acetobutylicum for the production of 1,3-PD from glycerol, turns it to be a flexible process that still requires optimization. It is possible to choose operating either on sugar or glycerol feedstocks, which is a very suitable characteristic in our days, due to fluctuations of the market prices of substrates.

Acknowledgements Part of this work was financially supported by European Committee Fifth Framework Programme Project (Contact $n^{\circ}$ QLRT-1999-01364). F. Mendes was supported by Fundação para a Ciência e a Tecnologia with a Ph.D. grant (SFRH/ BD/ 8337/ 2002).

\section{References}

Atiyeh H, Duvnjak Z (2003) Production of fructose and ethanol from cane molasses using Saccharomyces cerevisiae ATCC 36858. Acta Biotechnol 1:37-48

Barbirato F, Camarasa-Claret C, Bories A, Grivet JP (1995) Description of the glycerol fermentation by a new 1,3-propanediol producing microorganism: Enterobacter agglomerans. Appl Microbiol Biotechnol 43:786-793

Barbirato F, Himmi EH, Conte T, Bories A (1998) 1,3-Propanediol production by fermentation: an interesting way to valorize glycerin from the ester and ethanol industries. Ind Crops Prod 7:281-289

Biebl H, Marten S, Hippe H, Deckwer WD (1992) Glycerol conversion to 1,3-propanediol by newly isolated Clostridia. Appl Microbiol Biotechnol 36:592-597

Biebl H, Menzel K, Zeng AP, Deckwer WD (1999) Microbial production of 1,3-propanediol. Appl Microbiol Biotechnol 52:289-297

Boenigk R, Bowien S, Gottschalk G (1993) Fermentation of glycerol to 1,3-propanediol in continuous cultures of Citrobacter freundii. Appl Microbiol Biotechnol 38:453-457

Cameron DC, Altaras NE, Hoffman ML, Shaw AJ (1998) Metabolic engineering of propanediol pathways. Biotechnol Prog 14:116-125

Chandra R, Bharagava RN, Rai V (2008) Melanoidins as major colourant in sugarcane molasses based distillery effluent and its degradation. Bioresour Technol 99:4648-4660

Cheng KK, Zhang JA, Liu DH, Sun Y, Yang MD, Xu JM (2006) Production of 1,3-propanediol by Klebsiella pneumoniae from glycerol broth. Biotechnol Lett 28:1817-1821

Cordier H, Mendes F, Vasconcelos I, François JM (2007) A metabolic and genomic study of engineered Saccharomyces cerevisiae strains for high glycerol production. Metab Eng 9:364-378

Dabrock B, Bahl H, Gottschalk G (1992) Parameters affecting solvent production by Clostridium pasteuriano. Appl Environ Microbiol 58:1233-1239

Daniel R, Stuertz K, Gottschalk G (1995) Biochemical and molecular characterization of the oxidative branch of glycerol utilization by Citrobacter freundii. J Bacteriol 177:4392-4401

Forsberg CW (1987) Production of 1,3-propanediol from glycerol by Clostridium acetobutylicum and other Clostridium species. Appl Environ Microbiol 53:639-643

Fouad M, Ali AZ, Yassein M (1982) Utilisation of blackstrap molasses for the production of acetone and butanol by Clostridium acetobutylicum. Agro Wastes 4:291-304 
González-Pajuelo M, Andrade JC, Vasconcelos I (2004) Production of 1,3-propanediol by Clostridium butyricum VPI 3266 using a synthetic medium and raw glycerol. J Ind Microbiol Biotechnol 31:442-446

González-Pajuelo M, Meynial-Salles I, Mendes F, Andrade JC, Vasconcelos I, Soucaille P (2005) Metabolic engineering of Clostridium acetobutylicum for the industrial production of 1,3propanediol from glycerol. Metab Eng 7:329-336

González-Pajuelo M, Meynial-Salles I, Mendes F, Soucaille P, Vasconcelos I (2006) Microbial conversion of glycerol to 1,3propanediol: physiological comparison of a natural producer, Clostridium butyricum VPI 3266, and an engineered strain, Clostridium acetobutylicum DG1(pSPD5). Appl Environ Microbiol 72:96-101

Hartlep M, Hussmann W, Prayitno N, Meynial-Salles I, Zeng AP (2002) Study of two-stage processes for the microbial production of 1,3-propanediol from glucose. Appl Microbiol Biotechnol 60:60-66

Heux S, Cachon R, Dequin S (2006) Cofactor engineering in Saccharomyces cerevisiae: expression of a $\mathrm{H}_{2} \mathrm{O}$-forming $\mathrm{NADH}$ oxidase and impact on redox metabolism. Metab Eng 8:303-314

Hirschmann S, Koschik I, Baganz K, Vorlop KD (2005) Development of an integrated bioconversion process for the production of 1,3propanediol from raw glycerol water. Landbauforschung Völkenrode 55:261-267

Homann T, Tag C, Biebl H, Deckwer WD, Schink B (1990) Fermentation of glycerol to 1,3-propanediol by Klebsiella and Citrobacter strains. Appl Microbiol Biotechnol 33:121-126

Jiang L, Wang J, Liang S, Wang X, Cen P, Xu Z (2009) Butyric acid fermentation in a fibrous bed bioreactor with immobilized Clostridium tyrobutyricum from cane molasses. Bioresource Technol 100:3403-3409

Kumar P, Chandra R (2006) Decolourisation and detoxification of synthetic molasses melanoidins by individual and mixed cultures of Bacillus spp. Bioresource Technol 97:2096-2102

Kurian JV (2005) A new polymer platform for the future-Sorona $\left.{ }^{(}\right)$ from corn derived 1,3-propanediol. J Polymer Environ 13:159-167

Lagunas R, Dominguez C, Busturia A, Saez MJ (1982) Mechanisms of appearance of the Pasteur effect in Saccharomyces cerevisiae: inactivation of sugar transport system. J Bacteriol 152:19-25

Lloyd D, Kristensen B, Degn H (1983) Glycolysis and respiration in yeasts: the effect of ammonium ions studied by mass spectrometry. J Gen Microbiol 129:2125-2127

Ma Z, Rao Z, Xu L, Liao X, Fang H, Zhuge B (2009) Expression of DHA operon required for 1,3-PD formation in Escherichia coli and Saccharomyces cerevisiae. Curr Microbiol 60:191-198

Nakamura CE, Whited GM (2003) Metabolic engineering for the microbial production of 1,3-propanediol. Curr Opin Biotechnol 14:454-459

Németh A, Sevella B (2008) Development of a new bioprocess for production of 1,3-propanediol I.: modeling of glycerol bioconversion to 1,3-propanediol with Klebsiella pneumoniae enzymes. Appl Biochem Biotechnol 144:47-58
Papanikolaou S, Ruiz-Sanchez P, Pariset B, Blanchard F, Fick M (2000) High production of 1,3-propanediol from industrial glycerol by a newly isolated Clostridium butyricum strain. J Biotechnol 77:191-208

Papanikolaou S, Fakas S, Fick M, Chevalot I, Galiotou-Panayotou M, Komaitis M, Marc I, Aggelis G (2008) Biotechnological valorisation of raw glycerol discharged after bio-diesel (fatty acid methyl esters) manufacturing process: production of 1,3-propanediol, citric acid and single cell oil. Biomass Bioenerg 32:60-71

Rao Z, Ma Z, Shen W, Fang H, Zhuge J, Wang X (2008) Engineered Saccharomyces cerevisiae that produces 1,3-propanediol from Dglucose. J Appl Microbiol 105:1768-1776

Raynaud C, Sarçabal P, Meynial-Salles I, Croux C, Soucaille P (2003) Molecular characterization of the 1,3-propanediol operon of Clostridium butyricum encoding a novel coenzyme B12 independent glycerol dehydratase and a 1,3 propanediol dehydrogenase. Proc Natl Acad Sci 100:5010-5015

Remize F, Roustan JL, Sablayrolles JM, Barre P, Dequin S (1999) Glycerol overproduction by engineered Saccharomyces cerevisiae wine yeast strains leads to substantial changes in byproducts formation and to a stimulation of fermentation rate in stationary phase. Appl Environ Microbiol 65:143-149

Remize F, Barnavon L, Dequin S (2001) Glycerol export and glycerolphosphate dehydrogenase, but not glycerol phosphate, are rate limiting for glycerol production in Saccharomyces cerevisiae. Metab Eng 3:301-312

Schutz H, Radler F (1984) Anaerobic reduction of glycerol to propanediol-1,3 by Lactobacillus brevis and Lactobacillus buchneri. Syst Appl Microbiol 5:169-178

Sirianuntapiboon S, Prasertsong K (2008) Treatment of molasses wastewater by acetogenic bacteria BP103 in sequencing batch reactor (SBR) system. Bioresour Technol 99:1806-1815

Tondee T, Sirianuntapiboon S (2008) Decolorization of molasses wastewater by Lactobacillus plantarum No. PV71-1861. Bioresour Technol 99:6258-6265

van Dijken JP, Bauer J, Brambilla L, Duboc P, Francois JM, Gancedo C, Giuseppin ML, Heijnen JJ, Hoare M, Lange HC, Madden EA, Niederberger P, Nielsen J, Parrou JL, Petit T, Porro D, Reuss M, van Riel N, Rizzi M, Steensma HY, Verrips CT, Vindelov J, Pronk JT (2000) An interlaboratory comparison of physiological and genetic properties of four Saccharomyces cerevisiae strains. Enzyme Microb Technol 26:706-714

Vasconcelos I, Girbal L, Soucaille P (1994) Regulation of carbon and electron flow in Clostridium acetobutylicum grown in chemostat culture at neutral $\mathrm{pH}$ on mixtures of glucose and glycerol. J Bacteriol 176:1443-1450

Willke T, Vorlop K (2008) Biotransformation of glycerol into 1,3propanediol. Eur J Lipid Sci Technol 110:831-840

Zheng Y, Zhao L, Zhang J, Zhang H, Ma X, Wei D (2008) Production of glycerol from glucose by coexpressing glycerol-3-phosphate dehydrogenase and glycerol-3-phosphatase in Klebsiella pneumoniae. J Biosci Bioeng 105:508-512 